REVIEW ARTICLE

AFRICAN JOURNAL OF CLINICAL AND EXPERIMENTAL MICROBIOLOGY $\quad$ MAY $2013 \quad$ ISBN 1595-689X VOL 14(2) 2013

AJCEM/21317

COPYRIGHT 2013

AFR. J. CLN. EXPER. MICROBIOL 14(2): 101-104 http:/ / dx.doi.org/10.4314/ajcem.v14i2.10

\title{
URINE CULTURE CONTAMINATION: A ONE-YEAR RETROSPECTIVE STUDY AT THE NATIONAL HOSPITAL, ABUJA
}

\author{
Iregbu, KC.", Medugu, N., Abdullahi, N., Aigbe, AI., Modibbo, IF., Nwajiobi-Princewill, PI. \& Shettima, SA. \\ Department of Medical Microbiology and Parasitology, National Hospital, Abuja, P.M.B 425, Nigeria. \\ *Correspondence: Iregbu KC., Department of Medical Microbiology, National Hospital, Abuja. Nigeria. \\ Email: keniregbu@yahoo.co.uk
}

\begin{abstract}
Background: Urine culture contamination is a significant cause of delay in treatment of patients being investigated for urinary tract infection. Though contamination is not completely avoidable, several measures have been proven to decrease contamination rates. There are few studies detailing urine contamination rates in laboratories in Nigeria.

Aim: To determine the frequency and factors associated with urine culture contamination in samples submitted to the Medical Microbiology Laboratory in National Hospital Abuja (NHA).

Method: Retrospective study of urine culture contamination in which data from Medical Microbiology Laboratory from January 1 to December 312012 at National Hospital Abuja were reviewed. Patients' age, gender, location and urine culture result were assessed. Contamination rates for different genders, age groups and departments were assessed and results presented in simple averages and percentages.

Results: Overall contamination rate was $\mathbf{1 3 . 1 \%}$. Females had a contamination rate of $16.9 \%$, which was significantly higher than the contamination rate of $6.8 \%$ in males. The Gynaecology and Antenatal clinics had the highest contamination rates amongst departments with $22.5 \%$ and $21.3 \%$ respectively. Lowest contamination rates were in Emergency Paediatric Unit (EPU) and intensive Care Unit (ICU) with rates of $5.9 \%$ and $9.5 \%$ respectively. The female gender was found to be the most significant predictor of higher contamination rate.
\end{abstract}

Conclusion: Contamination rate of urine cultures in this study is unacceptably high. Appropriate interventions need to be instituted to reduce the current urine culture contamination rate in National Hospital Abuja.

Key Words: Urine, Contamination, National Hospital, Abuja.

\section{INTRODUCTION}

Contamination of urine cultures results from poor collection technique and or prolonged time from collection to processing (1). Suprapubic aspiration and straight catheter technique are the best methods to avoid contamination but they are invasive (2). Most urine specimens in adults and children are collected using the clean-catch midstream (CCMS) technique. Proper use of the CCMS technique results in colony counts which correlate with those of specimens collected via suprapubic aspiration (3). Bacterial contamination of urine often has important consequences; overuse of antibiotics, delay in instituting appropriate antibiotics, erroneous diagnosis and added cost of repeat cultures $(1,4)$.

Urine culture contamination has been defined in several ways. The College of American Pathologists (CAP) has defined it as 'any urine specimen that yields $>10^{5} \mathrm{cfu} / \mathrm{ml}$ of two or more different organisms' (1). Pure culture growth of bacteria in numbers $<10^{5}$ have been considered as contaminants in other studies $(5,6)$. The rate of urine culture contamination in some studies range from 2-37\% $(1,7,8,9)$.While possibly not being completely avoidable, rates can be reduced by instituting appropriate effective measures. This study was carried out to determine the baseline contamination rate in NHA to guide appropriate intervention measures.

\section{MATERIALS AND METHODS}

The study was designed to assess the frequency of bacterial contamination of urine cultures and elucidate factors associated with urine contamination. Laboratory data for urine cultures from January 1 to December 2012 were analyzed using Microsoft Excel. All culture were made on either CLED and blood agar plates or McConkey and blood agar plates and incubated in air for 16-24 hours in air. Variables analyzed were patient age, gender, location and urine culture result. Urine culture contamination as defined by CAP is adopted is our laboratory. Patients with specimens not specifying age, gender or urine culture results in register were excluded 
from the study. Factors that could potentially be associated with higher or lower urine contamination rates were identified. Selected variables were examined individually to determine if they were independently associated with urine culture contamination rate.

\section{RESULTS}

A total of 4448 specimen were received in the laboratory, out of which 2631 (59.2\%) met the inclusion criteria. The sample population was made up of 1593 (60.6\%) females and1038 (39.5\%) males.

Overall urine culture contamination rate was $13.1 \%$ $(345 / 2631)$. Contamination rate of the female subset was $16.9 \%$ while that of the male subset was $6.7 \%$ (Table 1 ).

TABLE 1: URINE CONTAMINATION RATES BYGENDER

\begin{tabular}{|l|l|l|l|}
\hline & Total No of Specimen & Number of Contaminated & Percent contaminated \\
\hline Male & 1037 & 70 & 6.6 \\
\hline Female & 1593 & 269 & 16.9 \\
\hline Total specimen & 2631 & 345 & 13.1 \\
\hline
\end{tabular}

$\mathbf{P}<0.0001$

Analysis of the age subset showed children aged less than two years had contamination rate of $10.5 \%$ while patients aged 2-60 years had a contamination rate of
$12.9 \%$. The contamination rate of patients over 60 years of age was $11.1 \%$. (Table 2 )

TABLE 2: URINE CONTAMINATION RATE BY SITE

\begin{tabular}{|l|l|l|l|}
\hline & Total Specimen & Number Contaminated & Percent contaminated \\
\hline EPU & & & 5.8 \\
\hline ICU & 255 & 15 & 9.5 \\
\hline GYNAE & 21 & 2 & 22.5 \\
\hline ANTENATAL & 178 & 40 & 21.3 \\
\hline INPATIENT & 150 & 32 & 13.3 \\
\hline OUTPATIENT & 1346 & 179 & 12.5 \\
\hline
\end{tabular}

The EPU and ICU had contamination rates of $5.5 \%$ and $9.5 \%$ respectively. Contamination rates of specimen from the Gynaecology and Antenatal subsets were $22.5 \%$ and
$21.3 \%$ respectively. The adult emergency department had a contamination rate of $13.8 \%$. The rate for inpatients was $13.3 \%$ while that of outpatients was. $12.5 \%$. (Table 3 )

TABLE 3: URINE CONTAMINATION RATE IN DIFFERENT AGE GROUPS

\begin{tabular}{|l|l|l|l|}
\hline Age & $\begin{array}{l}\text { Number of Contaminated Specimen } \\
(\mathrm{n})\end{array}$ & Total Specimen $(\mathrm{N})$ & Percent contaminated \\
\hline$<2 \mathrm{yr}$ & 12 & 114 & 10.5 \\
\hline $2-60 \mathrm{yr}$ & 306 & 2374 & 12.9 \\
\hline$>60 \mathrm{yr}$ & 12 & 117 & 11.1 \\
\hline $\mathrm{P}<0.01$ & & \\
\hline
\end{tabular}

\section{DISCUSSION}

This study was designed to elucidate the frequency of urine culture contamination and analyze factors associated with the rates.
Majority (60.0) of the urine specimens analyzed were from females. This increased rate of investigating females is because of their higher risk of having urinary tract infection $(1,10)$. 
Overall urine culture contamination rate in NHA for the period under study was found to be $13.1 \%$. The literature has widely varying estimates of urine contamination (1, $7,8,9)$; this variation may be because of the different characteristics of the populations studied - healthy males, healthy women, prepubescent females, uncircumcised males - and the different criteria used for defining urine culture contamination in the various studies. The largest study done on urine culture contamination rate, the CAP (1) study, used the same definition of urine culture contamination as this study and has the most similar patient characteristics. Median contamination rate in the CAP study was found to be $18.1 \%(1)$, with laboratories in the $90^{\text {th }}$ and $10^{\text {th }}$ percentiles of the study having average rates of $5.7 \%$ and $36.7 \%$ respectively. Thus, relative to that study, the urine culture contamination rate in NHA may appear to be within average. Due to the differing characteristics between this study and the others, no direct comparison can conveniently be made. The finding that females have significantly more urine contamination rate than males is consistent with previous findings $(1,5,6,10)$.

Patients of different ages had slightly different contamination rates; the trend towards higher contamination rates was seen in groups with a higher proportion of females. Although contamination rates differed markedly for different departments, the higher contamination rates were seen in sections with higher female population. This female dominance in urine contamination is likely due to the anatomical features of the external genitalia and its proximity to the perianal

\section{REFERENCES}

1) Valenstein, P., Meier, F. Urine culture contamination: a college of American Pathologists Q-Probes study of contaminated urine cultures in 906 institutions. Arch. Pathol. Lab. Med. 1998 Feb; 122: 123-9.

2) Wilson, M.L., Gaido, L. Laboratory diagnosis of urinary tract infections in adult patients. Clin. Infect. Dis. 2004; 38: 1150-1158.

3) Stamm, W. E., Counts, G. W., Running, K. R. Diagnosis of coliform infection in acutely dysuric women. N. Engl. J. Med. 1982; 307:4638.

4) Al-Orifi, F., McGillvray, D., Kramer, M. S. Urine culture from bag specimens in young children: are the risks too high? J.Pediatr. 2000 Aug; 137 (2): $221-226$

5) Vailancourt, S., McGilvray, D., Zhang, X., Kramer, M. S. To clean or not to clean: Effect on contamination rates in midstream urine collections in toilet trained children. Pediatrics 2007; 119(6) e1288-e1293.

6) Coulthard, M. G., Kalra, M., Lambert, J.H., Nelson, A., Smith, T., Perry, J. D. Redefining region. Patients in the hospital being sent for urine culture are rarely instructed on the collection technique (personal communications); it is therefore, most likely that the contaminations occurred at the time of collection as already established in previous studies $(1,11)$. Studies have shown that patients given instructions on proper collection have lower contamination rates than those who did not receive instructions $(6,7,8)$.

Similarly urine specimens were often observed to be delayed at varying points for a total of up to four to eight hours after collection without refrigeration or preservatives before processing. Delayed processing of urine specimen for more than 2 hours post collection results in increased rate of culture contamination unless specimens have been refrigerated or kept in a preservative $(1,11,12,13)$.In EPU, specimens were transported rapidly to the laboratory as against what obtains in other wards and outpatients where samples were kept for hours before being taken to the laboratory. This rapid transport from EPU may be one of the factors responsible for the lower contamination rate observed there, in addition to the very low number of females in this group.

It is concluded that the relatively high contamination rate seen in this study is unacceptable and can be reduced by giving proper instructions to patients and processing specimen within two hours of collection or stored in preservatives or refrigerated. There is need to set a benchmark contamination rate so as to enhance its use as a quality indicator in urine processing.

urinary tract infections by bacterial colony counts. Pediatrics 2010; 125(2): 335-341.

7) Saez-Llorens, X., Umana, M., Odio, C., Lohr, J. Bacterial contamination rates of non clean catch and clean catch midstream urine collections in uncircumcised boys. J. Pediatr. 1989; 114: 93-95.

8) Baerheim, A., Digranes, A., Hunskaar, S. Evaluatiion of urine sampling technique: Bacterial contamination of samples from women students. Br. J. Gen. Pract. 1992; 42:241-243.

9) Lohr, J. A., Portilla, M. G., Geuder, T. G., Dunn, M. L., Dudley, M. S. Bacterial contamination rates in voided urine collections in girls. J. Pediatr. 1989;114: 91-93.

10) Foxman, B. Epidemiology of urinary tract infections: incidence, morbidity, and economic costs. American Journal of Medicine, 2003; 49(2):53-70.

11) Hindman, R., Tronic, B., Bartlett, R. Effect of delay on culture of urine. J. Clin. Microbiol. 1976; 4(1): 102-103.

12) Jefferson, H., Dalton, H. P., Escobar, M. R., Allison, M. J. Transportation delay and the 
microbiological quality of clinical specimens. Am J ClinPathol. 1975 Nov; 64(5):689-693.

13) Diane, R., Doherty, L. F. Effect of perineal cleansing on contamination rate of mid-stream urine culture. Journal of Pediatric and Adolescent Gynecology 2006; 19(1): 31-34. 